\title{
Assessing Ecotoxicity of Aerosol Samples Using Higher Plants as Test Organisms
}

\author{
Nora Kováts*, Eszter Horváth, Bettina Eck-Varanka, Eszter Csajbók, Katalin Hubai, András \\ Hoffer \\ University of Pannonia, Institute of Environmental Sciences, Hungary. \\ * Corresponding author. Tel.: +36-88-624317; email: kovats@almos.uni-pannon.hu \\ Manuscript submitted November 12, 2018; accepted January 3, 2019. \\ doi: 10.17706/ijbbb.2019.9.3.166-172
}

\begin{abstract}
Plants are widely applied in the assessment of the ecological effects of airborne contaminants, using individual level symptoms such as growth inhibition or leaf injury. The same symptoms can be used in controlled ecotoxicological tests where the dose-effect relationships can be established and a quantitative estimation can be given on the toxic effect. In our study Cucumis sativus L. and Lycopersicon esculentum Mill. test plants were sprayed with the aqueous extract of urban aerosol samples, following the protocol as described by the No. 227 OECD GUIDELINE FOR THE TESTING OF CHEMICALS: Terrestrial Plant Test: Vegetative Vigour Test. After the termination of the test, on Day 21, fresh weight and leaf length were measured as end-points. It was found that the extract elucidated stimulatory effect on both fresh weight and leaf length in case of $C$. sativus, while $L$. esculentum remained less responsive. Our results are in concordance with literature data reporting on the nutrient content of atmospheric aerosol.
\end{abstract}

Key words: Aerosol, ecotoxicity, vegetative vigour test, nutrients.

\section{Introduction}

Atmospheric particulate matter with aerodynamic diameter less than $10 \mu \mathrm{m}$ (PM10) and $2.5 \mu \mathrm{m}$ (PM2.5) is now identified as one of the most dangerous pollutants on human health by the EU new directive on air quality (2008/50/CE). Trace metals and other aerosol constituents e.g. PAHs may play a major role concerning toxicity and ecotoxicity of atmospheric aerosol particles as they have a high affinity to the very fine and ultrafine aerosol fractions [1]. Urban airborne pollution has been well characterised from (human) toxicological aspects, also, the ecological effect of airborne contaminants have been extensively studied using plants as bioindicator organisms.

Responses of plants have been examined at different scale levels, from molecular systems to communities [2], [3]. On individual level, a wide range of end-points have been used, growth inhibition and visible leaf symptoms are amongst the most frequently applied [4], [5].

Bioindication studies, however, give only qualitative estimation on the magnitude of the problem. These studies are mostly based on the symptoms but neither the composition of contaminated air, nor concentration of individual pollutants can be estimated. Considering the relatively long exposure period, it might also be supposed that these factors are changing in time, showing diurnal and/or seasonal patterns. Concentration of certain compounds might also change due to atmospheric processes such as UV radiation. As such, high level of uncertainties are implied in bioindication or biomonitoring field work. 
On the contrary, ecotoxicological tests (or bioassays) are controlled, reproducible tests where ecological responses are determined quantitatively. Similar end-points can be used as in field studies, involving growth impairment. Ecotoxicity of the sample is most commonly expressed in the form of ECx value, that is, the (calculated) effective concentration which causes $\mathrm{x} \%$ of ecological effect.

Exposure can be achieved by for example placing test plants under chamber conditions, in this way plants are in direct contact with contaminated air. Fumigation chambers have been in use since the 1950's [6]. In these chambers, phytotoxic effect of either individual components such as polyaromatic hydrocarbons (PAHs) can be assessed [7], [8], but model gases can also be used as sample. Simulated diesel exhaust emissions were tested in a solardome fumigation facility on native herbaceous species [9], [10]. Viskari et al. (2000) used fumigation chamber to study the effects of motor vehicle exhaust gas on Norway spruce seedlings (Picea abies (L.) Karst) [11]. Effect of aerosol fraction can also be studied: in the experiment of Daresta et al. (2015) tomato (Solanum lycopersicum L.) plants were grown in PM10 collected on quartz fiber filters [12].

In our study, aqueous extract of urban aerosol sample was used as test material. Ecotoxicity of aqueous extract has been already tested on different test organisms, such as the bioluminescent bacterium Vibrio fischeri [13], the bacterium Pseudomonas putida [14] or the rotifer Brachionus calyciflorus [15]. The main aim of our study was to assess what detrimental effect aerosol extract might have on higher plants, or on the other hand, to evaluate the sensitivity of higher plants in such ecotoxicological tests.

\section{Material and Methods}

\subsection{Sample Collection}

PM10 aerosol samples were collected at the main observatory of the Hungarian Meteorological Service (at Gilice square) in Budapest, Hungary. The sampling site is located in a suburban area of the city, thus it is a residential background station. The aerosol samples were collected by a high volume sampler Digitel (DHA-80) on glass fibre filters. 12 samples were collected between 25.12.2014 and 06.01.2015, the sampling time was 24 hours.

\subsection{Sample Preparation}

To extract the water soluble compounds of the samples, the halves of each filter were cut in pieces and placed in beaker filled with $1000 \mathrm{ml}$ high purity (MilliQ) water. After stirring the filter pieces in water several times, the beaker was covered and the extraction continued for 24 hours. The extract was then filtered on $0.45 \mu \mathrm{m}$ pore size filter and stored in a freezer until use.

\subsection{Ecotoxicity Testing}

Following sample preparation ecotoxicity assessment was carried out as described in the No. 227 OECD GUIDELINE FOR THE TESTING OF CHEMICALS: Terrestrial Plant Test: Vegetative Vigour Test (hereinafter referred to as 'Guideline'). The Guideline was originally developed to test general chemicals, biocides and crop protection products and it has actually been used for phytotoxicity testing for herbicide regulation. The test assesses the potential effects on plants by spraying the test substance on the leaves and above-ground portions of plants. After application, the plants are evaluated against untreated control plants for effects on vigour and growth. Test endpoints used were shoot weight and shoot height. Cucumis sativus L. (cucumber) and Lycopersicon esculentum Mill. (tomato) were selected as test organism (the Guideline gives list of (crop) species recommended for testing in its Annex 2). Test conditions were as specified by the Guideline (temperature: $22^{\circ} \mathrm{C} \pm 10^{\circ} \mathrm{C}$; humidity: $70 \% \pm 25 \%$; photoperiod: minimum $16 \mathrm{~h}$ light; light intensity: $350 \pm 50$ $\mu \mathrm{E} / \mathrm{m} 2 / \mathrm{s}$ ), test duration (exposure) was 21 days.

Test plants were grown in pots of $15 \mathrm{~cm}$ diameter from seeds to the 2 true leaf stage. After thinning, 2 
plants were used per $15 \mathrm{~cm}$ container. Measurements were done in 5 replicates (by replicate one pot is meant). Spray volume of $5 \mathrm{ml}$ was applied for each container/treatment, using a CONXIN Q1P-CX01-380 portable electric paint spray gun. The test was terminated on Day 22, fresh weight and shoot length were measured. During the test, pots were repositioned periodically to minimize variability in growth of the plants. Watering was done carefully under the foliage.

\section{Results and Discussion}

For C. sativus, Fig. 1. and 2. show the average length of leaves in the test group in comparison to the control and the average fresh biomass. As it can be seen, the extract had a stimulatory effect on both fresh weight and leaf length. Stimulatory effect indicates the presence of nutrients. Atmospheric aerosol particles and/or their aqueous extracts contain important plant nutrients.

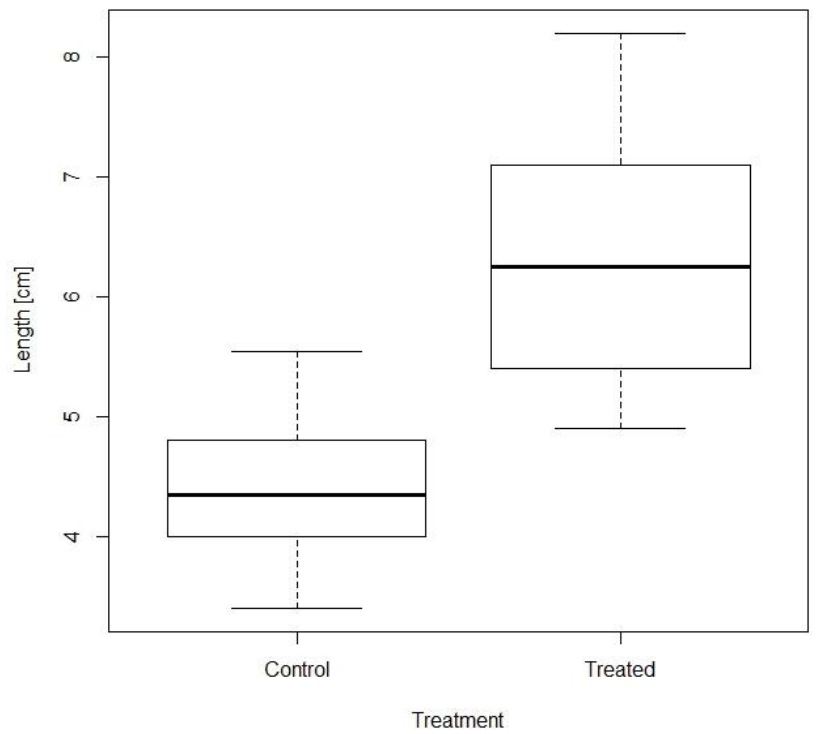

Fig. 1. Average length of leaves in the test group in comparison to the control in C. sativus.

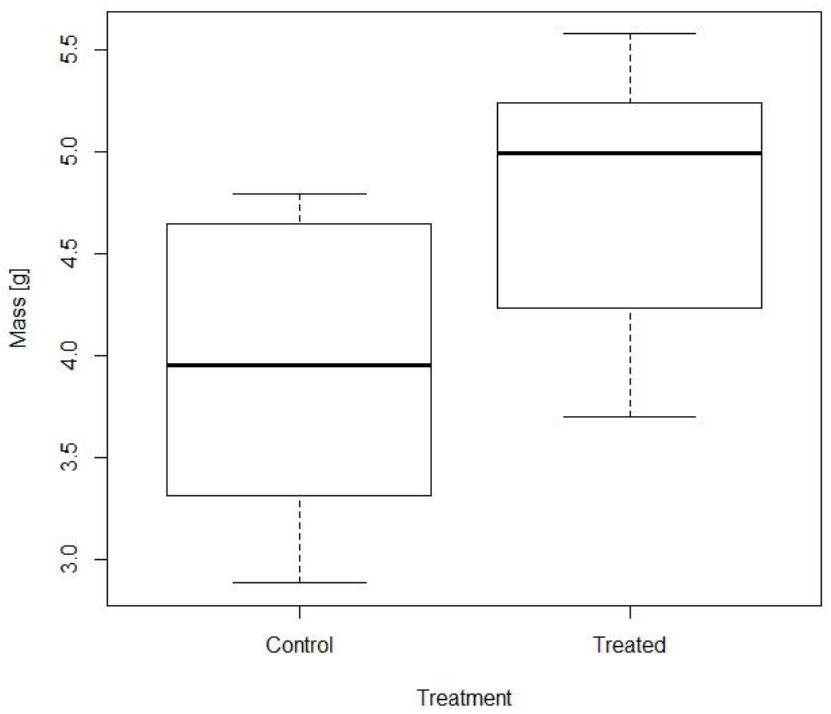

Fig. 2. Average biomass in the test group in comparison to the control C. sativus.

The main water soluble nitrogen containing compounds of the atmospheric aerosol are the ammonium and the nitrate. These compounds present in considerable amount in atmospheric aerosol: according to 
Lanz et al., 2010 and Waked et al., 2014, the mass concentration of ammonium is 10-15\% of the particulate mass and that of the nitrate is $10-30 \%$. Potassium and sulphate are also important inorganic components of the PM10. The mass concentration of sulphate is about 10-20\% [16], [17].

On the other hand, no statistically significant differences were found in case of L. esculentum (Fig. 3. and Fig. 4.). Although both species are recommended by the Guideline, L. esculentum has been more often used in experimental studies where detrimental effects of air pollution was assessed [18]-[20].

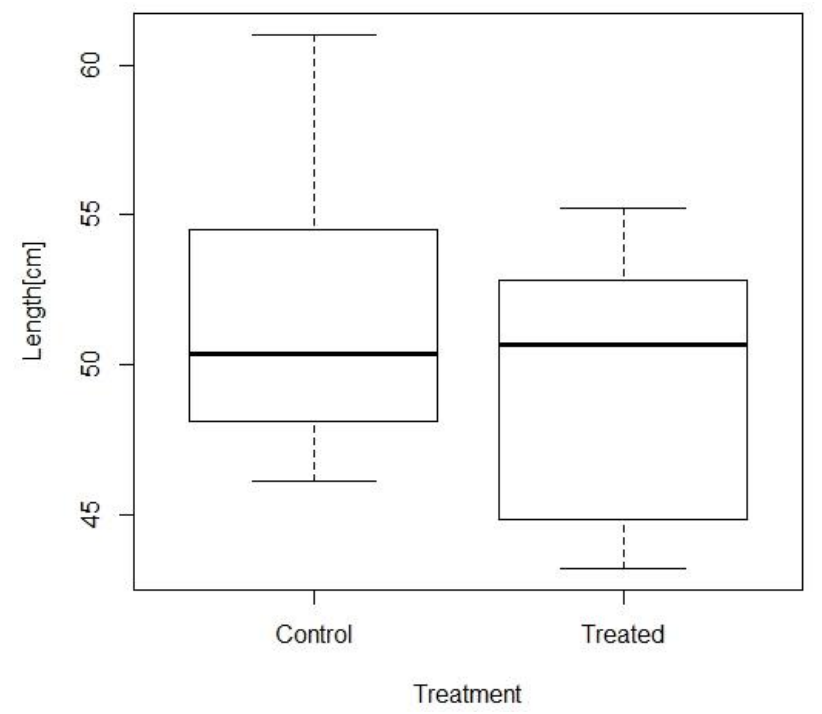

Fig. 3. Average length of leaves in the test group in comparison to the control in L. esculentum.

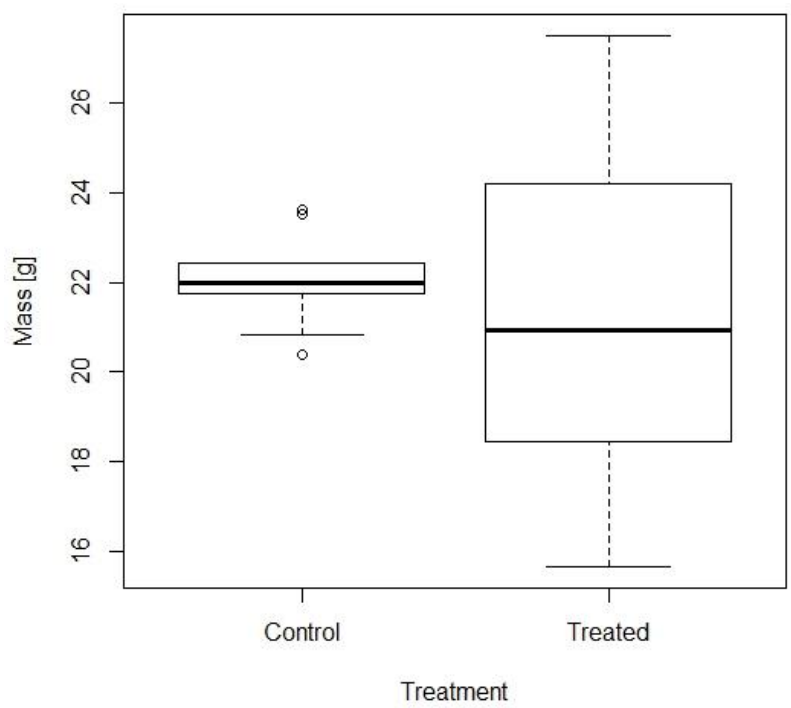

Fig. 4. Average biomass in the test group in comparison to the control L. esculentum.

Very few comparative studies are available on the sensitivity of the two test species. Ahammed et al. (2012) for example assessed the effects of foliar application of Phenanthrene (PHE) on shoot and root weight of five vegetables [19]. Sensitivity expressed as the average percentage decrease in shoot weight (fresh and dry) was in the following order: pakchoi - cucumber - lettuce - tomato - cabbage. The higher sensitivity of cucumber is in concordance with our results.

Based on the data, no toxic effect was detected. It is somewhat in contradiction with literature data: Roig et al. (2013) for example when using aqueous extract to assess the ecotoxicity of airborne pollutants in 
different parts of Catalonia (Spain) found significant correlation between toxicity values and most pollutants (metals and polychlorinated dibenzo-p-dioxins and dibenzofurans). Silva et al. (2014) evaluated the toxicity of aqueous extracts of ash from forest fires in the Mediterranean region (Catena, Spain) and could determine a clear spatial pattern of diffuse contamination for downstream water bodies. In both studies the bioassay based on the bioluminescence inhibition of the marine bacterium Vibrio fischeri was used [13], [21].

The question arises if growth inhibition can be an adequately sensitive end-point. Growth impairment in general can be considered as an ultimate symptom. Biomass production is influenced by the efficiency of photosynthesis, expressed e.g. as net $\mathrm{CO} 2$ assimilation (Pn). Biomass reduction can be explained by the inhibition of photosynthesis which implies that changes in photosynthetic pigment concentration can be an earlier warning sign for deleterious effects. Photosynthetic activity has in fact been a widely applied end-point in estimating the response of plants to different environmental stressors, including air pollutants. Decreased levels of chlorophyll a and b was already reported by Rabe and Kreeb in 1979 [22]. Huang et al. assessed the photoinduced toxicity of PAHs on C. sativus after foliar application and found that shoot biomass and chlorophyll content reduction were the most significant symptoms [23]. Early field studies also supported the reduced chlorophyll content in stressed leaves [24]. As a response to air pollution, Fourati et al. (2017) found that the values of the photosynthetic pigments, chlorophyll and carotenoids were generally higher in plants from control sites than those from polluted sites [25]. Damage of photosynthetic pigments caused by autopollution was experienced in a study of Verma and Singh (2006) [26]. Biochemical end-points, including the concentrations of chlorophyll proved more sensitive than fresh weight when phytotoxicity of two PAHs (anthracene and benzo[k]fluoranthene) was assessed [27].

In general, inclusion of the concentration of different photosynthetic pigments into the end-points recommended by the Guideline should not only be beneficial due to the sensitivity of these markers, but also, measurement of these pigments is relatively cost-effective and detailed protocols are available for measuring technics.

\section{Conclusions}

It should be stressed that the Guideline prescribes only one treatment which might not represent adequately long-term or frequent air pollution episodes. On one hand, stimulating effect of the nutrients present are already shown by our test system, though sensitivity of the two test species differ. On the other hand, however, our results might indicate that aqueous extract of aerosol samples at least after one single treatment will not elucidate (eco)toxic effect. Sensitivity of the system, however, might be enhanced by repeated treatments, providing also a refinement to the Guideline. The Guideline can also be improved by the inclusion of further end-points, such as biochemical, morphological traits or measurement of accumulation.

\section{Acknowledgements}

This work was supported by the BIONANO_GINOP-2.3.2-15-2016-00017 project. The authors thank the Hungarian Air Quality Reference Center for the aerosol samples.

\section{References}

[1] Moreno, T., Querol, X., Alastuey, A., Viana, M., Salvador, P., Sanchez. C. A., Artinano, B., Rosa, J., \& Gibbons, W. (2006). Variations in atmospheric PM trace metal content in Spanish towns: illustrating the chemical complexity of the inorganic urban aerosol cocktail. Atmospheric Environment, 40, 6791-6803.

[1] Alkio, M., Tabuchi, T. M., Wang, X., \& Colón-Carmona, A. (2005). Stress responses to polycyclic aromatic 
hydrocarbons in Arabidopsis include growth inhibition and hypersensitive response-like symptoms. Journal of Experimental Botany, 56(421), 2983-2994.

[2] Payne, R. J., Stevens, C. J., Dise, N. B., Gowing, D. J., Pilkington, M. G., Phoenix, G. K., Emmett, B. A., \& Ashmore, M. R. (2011). Impacts of atmospheric pollution on the plant communities of British acid grasslands. Environmental Pollution, 159, 2602-2608.

[3] Günthardt-Goerg, M. S., \& Vollenweider, P. (2007). Linking stress with macroscopic and microscopic leaf response in trees: New diagnostic perspectives. Environmental Pollution, 147, 467-488.

[4] Bharti, S. K., Trivedi, A., \& Kumar, N. (2018). Air pollution tolerance index of plants growing near an industrial site. Urban Climate, 24, 820-829.

[5] Haagen-Smit, A.J., Darley, E.F., Zaitlin, M., Hull, H., \& Noble, W. (1952). Investigation on injury to plants from air pollution in the Los Angeles area. Plant Physiology, 27(1), 18-34.

[6] Oguntimehin, I., Kondo, H., \& Sakugawa, H. (2010). The use of Sunpatiens (Impatiens spp.) as a bioindicator of some simulated air pollutants - Using an ornamental plant as bioindicator. Chemosphere, 81, 273-281.

[7] Desalme, D., Binet, P., Epron, D., Bernard, N., Gilbert, D., Toussaint, M. L., Plain, C., \& Chiapusio, G. (2011). Atmospheric phenanthrene pollution modulates carbon allocation in red clover (Trifolium pratense L.). Environmental Pollution, 159, 2759-2765.

[8] Honour, S. L., Bell, J. N. B., Ashenden, T. W., Cape, J. N., \& Power, S. A. (2009). Responses of herbaceous plants to urban air pollution: Effects on growth, phenology and leaf surface characteristics. Environmental Pollution, 157, 1279-1286.

[9] Bell, J. N. B., Honour, S. L., \& Power, S. A. (2011). Effects of vehicle exhaust emissions on urban wild plant species. Environmental Pollution, 159, 1984-1990.

[10] Viskari, E.-L., Surakka, J., Pasanen, P., Mirme, A., Kössi, S., Ruuskanen, J., \& Holopainen, J. K. (2000). Responses of spruce seedlings (Picea abies) to exhaust gas under laboratory conditions - I plant-insect interactions. Environmental Pollution, 107(1), 89-98.

[11] Daresta, B. E., Italiano, F., Gennaro, G., Trotta, M., Tutino, M., \& Veronico, P. (2015). Atmospheric particulate matter (PM) effect on the growth of Solanum lycopersicum cv. Roma plants. Chemosphere, 119, 37-42.

[12] Roig, N., Sierra, J., Rovira, J., Schuhmacher, M., Domingo, J. L., \& Nadal, M. (2013). In vitro tests to assess toxic effects of airborne PM10 samples. Correlation with metals and chlorinated dioxins and furans. Science of the Total Environment, 443, 791-797.

[13] Filep, Á., Drinovec, L., Palágyi, A., Manczinger, L., Vágvölgyi, Cs., Bozóki, Z., Hitzenberger, R., \& Szabó, G. (2015). Source specific cyto- and genotoxicity of atmospheric aerosol samples. Aerosol and Air Quality Research, 15, 2325-2331.

[14] Verma V., Rico-Martinez R., Kotra N., Rennolds C., Liu J., Snell T. W., \& Weber R. J. (2013). Estimating the toxicity of ambient fine aerosols using freshwater rotifer Brachionus calyciflorus (Rotifera: Monogononta). Environmental Pollution, 182, 379-384.

[15] Lanz, V. A., Prevot, A. S. H., Alfarra, M. R., Weimer, S., Mohr, C., DeCarlo, P. F., Gianini, M. F. D., Hueglin, C., Schneider, J., Favez, O., D'Anna, B., George, C., \& Baltensperger, U. (2010). Characterization of aerosol chemical composition with aerosol mass spectrometry in Central Europe: An overview. Atmospheric Chemistry and Physics, 10, 10453-10471.

[16] Waked, A., Favez, O., Alleman, L. Y., Piot, C., Petit, J. E., Delaunay, T., Verlinden, E., Golly, B., Besombes, J. L., Jaffrezo, J. L., \& Leoz-Garziandia, E. (2014). Source apportionment of PM10 in a north-western Europe regional urban background site (Lens, France) using positive matrix factorization and including primary biogenic emissions. Atmospheric Chemistry and Physics, 14, 3325-3346. 
[17] Oguntimehin, I., Eissa, F., \& Sakugawa H. (2010). Negative effects of fluoranthene on the ecophysiology of tomato plants (Lycopersicon esculentum Mill) Fluoranthene mists negatively affected tomato plants. Chemosphere, 78, 877-884.

[18] Ahammed, G. J., Wang, M. M., Zhou, Y. H., Xia, X. J., Mao, W. H., Shi, K., \& Yu, J. Q. (2012). The growth, photosynthesis and antioxidant defense responses of five vegetable crops to phenanthrene stress. Ecotoxicology and Environmental Safety, 80, 132-139.

[19] Ahammed, G. J., Yuan, H. L., Ogweno, J. O., Zhou, Y. H., \& Xia, X. J. (2012). Brassinosteroid alleviates phenanthrene and pyrene phytotoxicity by increasing detoxification activity and photosynthesis in tomato. Chemosphere, 86, 546-555.

[20] Silva, V., Pereira, J. L., Campos, I., Keizer, J. J., Gonçalves, F., \& Abrantes, N. (2014). Toxicity assessment of aqueous extracts of ash from forest fires. Catena, 135, 401-408.

[21] Rabe, R., \& Kreeb, K. H. (1979) Enzyme activities and chlorophyll and protein content in plants as indicators of air pollution. Environmental Pollution, 19, 119-137.

[22] Huang, X. D., Zeiler, L. F., Dixon, D. G., \& Greenberg, B. M. (1996). Photoinduced toxicity of PAHs to the foliar regions of Brassica napus (Canola) and Cucumis sativus (Cucumber) in simulated solar radiation. Ecotoxicology and Environmental Safety, 35, 190-197.

[23] Pandey, J., \& Pandey, U. (1994). Evaluation of air pollution phytotoxicity in a seasonally dry tropical urban environment. Environmental Monitoring and Assessment, 33(3), 195-213.

[24] Fourati, R., Scopa, A., Ahmed, C. B., Abdallah, F. B., Terzano, R., Gattullo, C. E., Allegretta, I., Galgano, F., Caruso, M. C., \& Sofo, A. (2017). Leaf biochemical responses and fruit oil quality parameters in olive plants subjected to airborne metal pollution. Chemosphere, 168, 514-522.

[25] Verma, A., \& Singh, S. N. (2006). Biochemical and ultrastructural changes in plant foliage exposed to auto-pollution. Environmental Monitoring and Assessment, 120, 585-602.

[26] Wieczorek, J., Sienkiewicz, S., Pietrzak, M., \& Wieczorek, Z. (2015). Uptake and phytotoxicity of anthracene and benzo[k]fluoranthene applied to the leaves of celery plants (Apium graveolens var. secalinum L.). Ecotoxicology and Environmental Safety, 115, 19-25.

Nora Kováts was born in Miskolc (Hungary), in 1964. She graduated in biology at the Kossuth Lajos University, Debrecen, Hungary. Recent Nora Kováts is associate professor at the University of Pannonia, Institute of Environmental Sciences, Veszprém, Hungary. Nora Kováts's field of expertise covers ecotoxicity assessment of airborne contaminants. Nora Kováts's reference papers: Kováts, N., \& Horváth, E. (2016). Bioluminescence-based assays for assessing eco- and genotoxicity of airborne emissions. Luminescence, 31/4, 918-923; Kováts, N., Ács, A., Ferincz, Á., Kovács, A., Horváth, E., Kakasi, B., et al. (2013). Ecotoxicity assessment of exhaust gases from diesel-powered vehicles. Environmental Monitoring and Assessment, 185:(10), 8707-8713; Kováts, N., Ács, A., Kovács, A., Ferincz, Á., Turóczi, B., \& Gelencsér, A. (2012). Direct contact test for estimating the ecotoxicity of aerosol samples. Environmental Toxicology and Pharmacology, 33, 284-287. 